\title{
PRECURSORY SLOPE DEFORMATION AROUND LANDSLIDE AREA DETECTED BY INSAR THROUGHOUT JAPAN
}

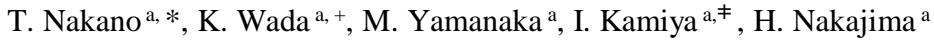 \\ ${ }^{a}$ Geospatial Information Authority of Japan, 1 Kitasato, Tsukuba, Ibaraki, Japan - \\ (nakano-t96fj, wada-k96ex, yamanaka-m96ah, kamiya-i96dv, nakajima-h96pm)@mlit.go.jp
}

SpS14 - FIG, Imaging Geodesy

KEY WORDS: InSAR, landslide, precursory slope deformation, field survey

\begin{abstract}
:
Interferometric Synthetic Aperture Radar (InSAR) technique is able to detect a slope deformation around landslide (e.g., Singhroy et al., 2004; Une et al., 2008; Riedel and Walther, 2008; Sato et al., 2014). Geospatial Information Authority (GSI) of Japan has been performing the InSAR analysis regularly by using ALOS/PALSAR data and ALOS-2/PALSAR-2 data throughout Japan. There are a lot of small phase change sites except for crustal deformation with earthquake or volcano activity in the InSAR imagery. Most of the phase change sites are located in landslide area. We conducted field survey at the 10 sites of those phase change sites. As a result, we identified deformation of artificial structures or linear depressions caused by mass movement at the 9 sites. This result indicates that InSAR technique can detect on the continual deformation of landslide block for several years. GSI of Japan will continue to perform the InSAR analysis throughout Japan. Therefore, we will be able to observe and monitor precursory slope deformation around landslide areas throughout Japan.
\end{abstract}

\section{INTRODUCTION}

Synthetic Aperture Radar (SAR) data is able to provide detailed and spatially comprehensive ground information. Interferometric SAR (InSAR) enables us to detect ground deformation with high precision by InSAR imagery (e.g., Massonnet and Feigl, 1998; Bürgmann et al., 2000). The InSAR imageries show the range change between the ground and the satellite, that is, the line-of-sight (LOS) displacement from phase difference. Satellite InSAR is able to detect ground deformation of several millimetres to several centimetres with several meters to dozens of meters resolution typically.

Geospatial Information Authority (GSI) of Japan has been performing the InSAR analysis regularly by using ALOS/PALSAR data and ALOS-2/PALSAR-2 data to detect crustal deformation induced by large earthquake, volcanic activity and land subsidence, etc. (e.g. Amagai et al., 2007; Suzuki et al., 2008; Tobita et al., 2011; Kobayashi et al., 2011; Kobayashi et al., 2015). ALOS was operated from January 2006 to May 2011, and ALOS-2 has been operated since May 2014. Both have L-band radar.

In Addition, InSAR technique is able to detect a slope deformation around landslide (e.g. Singhroy et al., 2004; Une et al., 2008; Riedel and Walther, 2008; Sato et al., 2012). InSAR analysis of GSI of Japan by using ALOS/PALSAR data and ALOS-2/PALSAR-2 data cover whole of Japan. There are a lot of small phase change sites except for crustal deformation with earthquake or volcano activity in the InSAR imagery. Most of the phase change sites are located in landslide area. Therefore, it is supposed that these phase changes are generated by slight slope deformation like precursory landslide. So, we conducted field survey at the 10 sites of those phase change sites and investigated deformation of artificial structures or topography with gravity sliding.

\section{INSAR ANALYSIS THROUGHOUT JAPAN}

\subsection{Data and Analysis}

We used ALOS/PALSAR data from January 2006 to May 2011 and ALOS-2/PALSAR-2 data from May 2014 to October 2015. The ALOS/PALSAR data was observed from descending (D) and ascending (A) orbits. The ALOS-2/PALSAR-2 data was observed from right side of descending orbit (DR), left side of descending orbit (DL), right side of ascending orbit (AR) and left side of ascending orbit (AL).

We used InSAR imageries throughout Japan which analysed regularly. The InSAR analysis was conducted by using unique "GSISAR" software (Fujiwara and Tobita, 1999; Tobita et al.,

\begin{tabular}{|c|c|c|c|c|c|c|}
\hline Site & $\begin{array}{c}\begin{array}{c}\text { Observation date } \\
\text { (Master/Slave) }\end{array} \\
.\end{array}$ & Satellite/Sensor & $\begin{array}{c}\text { Flight } \\
\text { Dir. }\end{array}$ & $\begin{array}{c}\begin{array}{c}\text { Beam } \\
\text { Dir. }\end{array} \\
\text {. }\end{array}$ & $\begin{array}{l}\text { Off-nadir } \\
\text { angle (deg) }\end{array}$ & Bperp (m) \\
\hline 1. Shizuoka & $\begin{array}{l}2008.09 .05 / 2008.10 .21 \\
2009.09 .08 / 2009.10 .24\end{array}$ & ALOS/PALSAR & D & $\mathrm{R}$ & $\begin{array}{l}34.3 \\
34.3\end{array}$ & $\begin{array}{c}-36 \\
+306\end{array}$ \\
\hline 2. Matsumoto & 2008.07.20/2009.09.07 & ALOS/PALSAR & A & $\mathrm{R}$ & 34.3 & +201 \\
\hline 3. Tenryu & $2010.03 .27 / 2010.11 .12$ & ALOS/PALSAR & A & $\mathrm{R}$ & 34.3 & +262 \\
\hline 4. Iida & 2008.07.20/2009.09.07 & ALOS/PALSAR & A & $\mathrm{R}$ & 34.3 & +202 \\
\hline 5. Ohshika & $2008.07 .20 / 2009.09 .07$ & ALOS/PALSAR & A & $\mathrm{R}$ & 34.3 & +202 \\
\hline 6. Totsugawa & $\begin{array}{l}2010.05 .18 / 2010.08 .18 \\
2010.06 .04 / 2010.09 .04\end{array}$ & ALOS/PALSAR & D & $\mathrm{R}$ & 34.3 & $\begin{array}{r}+36 \\
+261\end{array}$ \\
\hline 7. Tanabe & $2010.05 .05 / 2010.09 .20$ & ALOS/PALSAR & A & $\mathrm{R}$ & 34.3 & +326 \\
\hline 8. Motoyama-a & 2014.08.06/2015.09.02 & $\begin{array}{l}\text { ALOS-2/ } \\
\text { PALSAR-2 }\end{array}$ & D & $\mathrm{R}$ & 29.1 & -54 \\
\hline 9. Motoyama-b & $2014.08 .06 / 2015.09 .02$ & $\begin{array}{l}\text { ALOS-2/ } \\
\text { PALSAR-2 }\end{array}$ & D & $\mathrm{R}$ & 29.1 & -54 \\
\hline 10. Ino & $2014.09 .21 / 2015.06 .28$ & $\begin{array}{l}\text { ALOS-2/ } \\
\text { PALSAR-2 }\end{array}$ & A & $\mathrm{R}$ & 35.4 & -305 \\
\hline
\end{tabular}

Table 1. Specification of InSAR imageries of 10 sites in this paper

\footnotetext{
* Corresponding author.

+ Present affiliation: Ministry of Education, Culture, Sports, Science and Technology, Japan

₹ Present affiliation: Japan Digital Road Map Association
} 
1999; Fujiwara et al., 1999; Tobita, 2003). The specification of InSAR imageries referred for field survey on 10 sites in this paper are shown in Table 1.

\subsection{Interpretation of signal of slope deformation}

We interpreted and extracted the signal (phase change) of slope deformation on the InSAR imageries. The main rule of interpretation is as follows.

1) Line-of-sight (LOS) displacement is approximately $3 \mathrm{~cm}$ over.

2) Size of phase change is approximately $150 \mathrm{~m}$ by $150 \mathrm{~m}$ over.

3) Coherence of InSAR imagery is good.

4) Phase change zone has continuity and high density.

5) Not water and marsh area.

6) Not quarry area.

7) Similar phase change is not appeared on the same direction slope generally.

8) Phase change is no correlation with elevation and topography.

9) Boundary of phase change zone is inconsistent with boundary of land-use or vegetation.

10) Phase change is able to identify around same zone on the plural InSAR imageries of difference pair. (in case of ALOS-2/PALSAR-2)

11) Phase change is located on mountain or hill slope.

12) The direction of phase change is consistent with direction of slope.

13) The location of phase change is consistent with area of landslide topography and vulnerable geology.

\section{FINDINGS}

As a result of interpretation of the signal of slope deformation, we extracted 117 sites and 79 sites from ALOS/PALSAR interferograms and ALOS-2/PALSAR-2 interferograms respectively. We conducted field survey at the 10 sites of those from 2013 to 2016 (Figure 1). The 7 sites were extracted from ALOS/PALSAR interferograms, and the 3 sites were extracted from ALOS-2/PALSAR-2 interferograms (Table 1).

In this paper, we introduce the 3 cases $(2$ cases of ALOS/PALSAR and 1 case of ALOS-2/PALSAR-2) of those.

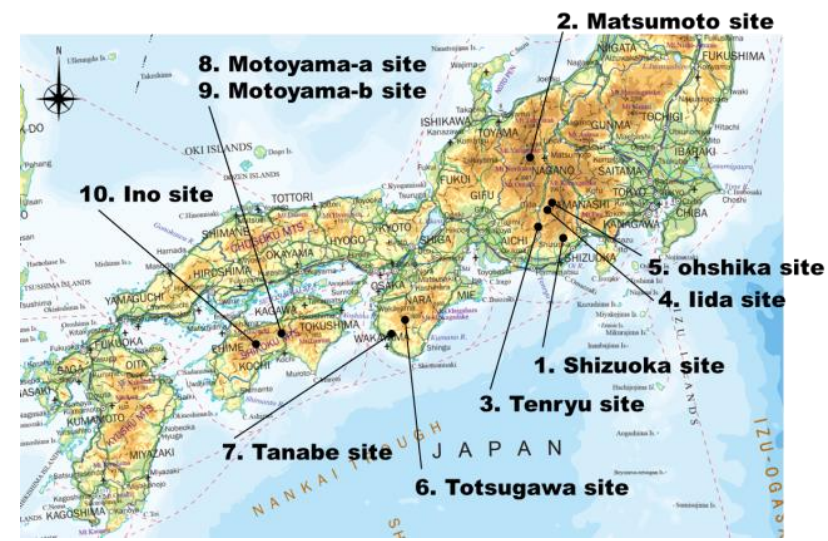

Figure 1. Location of field survey sites (on GSI Maps)

\subsection{Case of ALOS/PALSAR data}

3.1.1 1. Shizuoka site: InSAR imageries in Shizuoka site are shown in Figure 2. Change of LOS of approximately 3-4 $\mathrm{cm}$ in the direction of away from satellite was observed between September 5, 2008 and October 21, 2008 (upper figure in Figure 2). Change of LOS of approximately $7-8 \mathrm{~cm}$ in the direction of away from satellite was observed between September 8, 2009 and October 24, 2009 at the same position as upper figure (lower figure in Figure 2). There is landslide block around the phase change area. We surveyed on site in June 25, 2013, and we identified collapse of the landslide (Figure 3). Because the landslide didn't collapse in aerial photo on November 2012, it is estimated that the landslide collapsed between November 2012 and June 2013. Therefore, it can be said that InSAR technique was able to detect the precursory slope deformation of landslide block before the final landslide collapse of 2013.
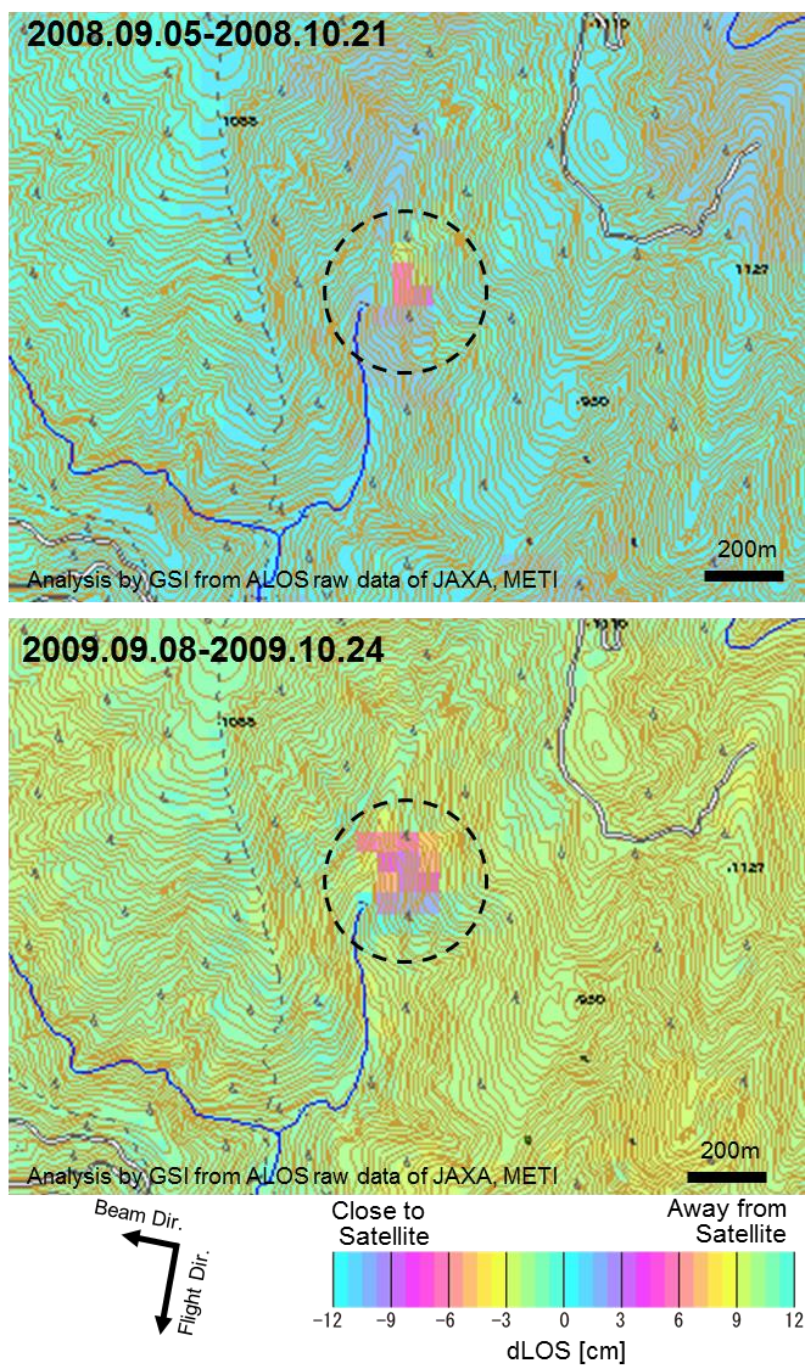

Figure 2. InSAR imageries on GSI Maps in Shizuoka site. Upper figure is InSAR imagery between September 5, 2008 and October 21, 2008. Lower figure is InSAR imagery between September 8, 2009 and October 24, 2009. 


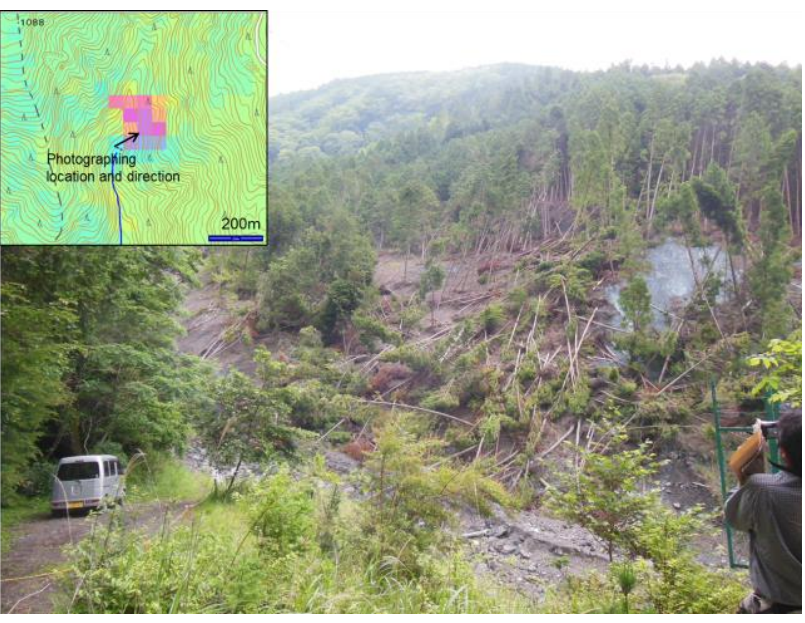

Figure 3. Field photo of landslide collapse in Shizuoka site (June 25, 2013).

3.1.2 7. Tanabe site: InSAR imagery and field photos in Tanabe site are shown in Figure 4 and Figure 5, respectively. Changes of LOS of approximately $3 \mathrm{~cm}$ in the direction of away from satellite was observed from May to September in 2010 at the landslide site. At this site, road located underneath landslide block was replaced (Photo 1 in Figure 4). Moreover, fresh open cracks of several centimetres width were found out on mortar spraying wall around the terminal part of landslide block by our field survey in December 2014 (Photo 2 in Figure 4). These fresh open cracks were caused by the swelling of terminal part of landslide block. Also, changes of LOS of approximately $5 \mathrm{~cm}$ in the direction of away from satellite was detected in the InSAR imagery from September 2014 to February 2015 by ALOS-2/PALSAR-2 data too. The residents around this landslide block told us that slope deformation have started from spring of 2010. This result indicates that InSAR technique can detect on the continual deformation of landslide block for several years.

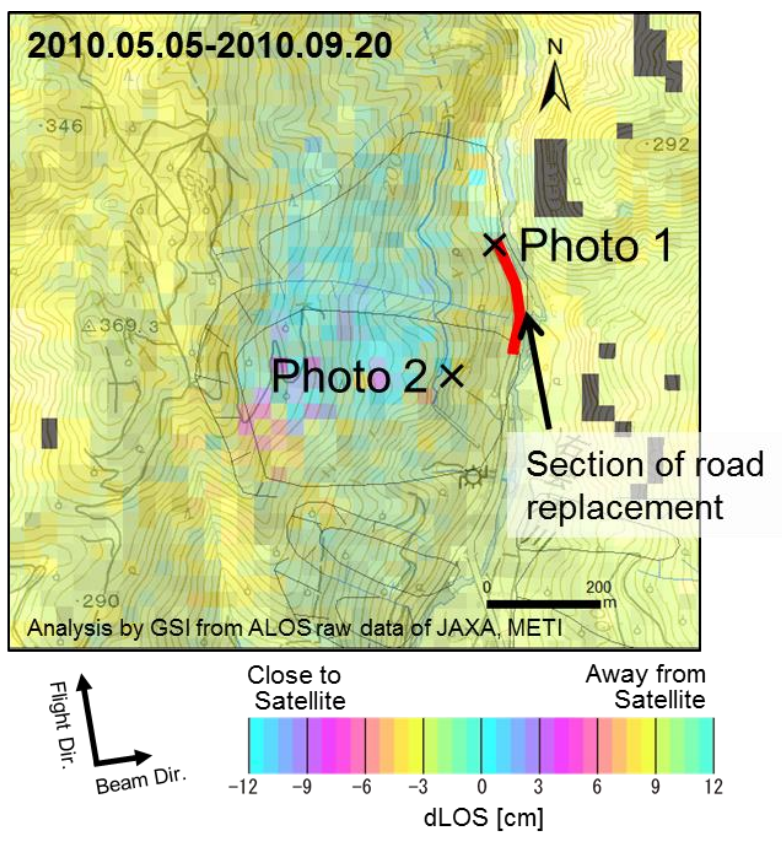

Figure 4. InSAR imagery between May 5, 2010 and September 20, 2010 on GSI Maps in Tanabe site.
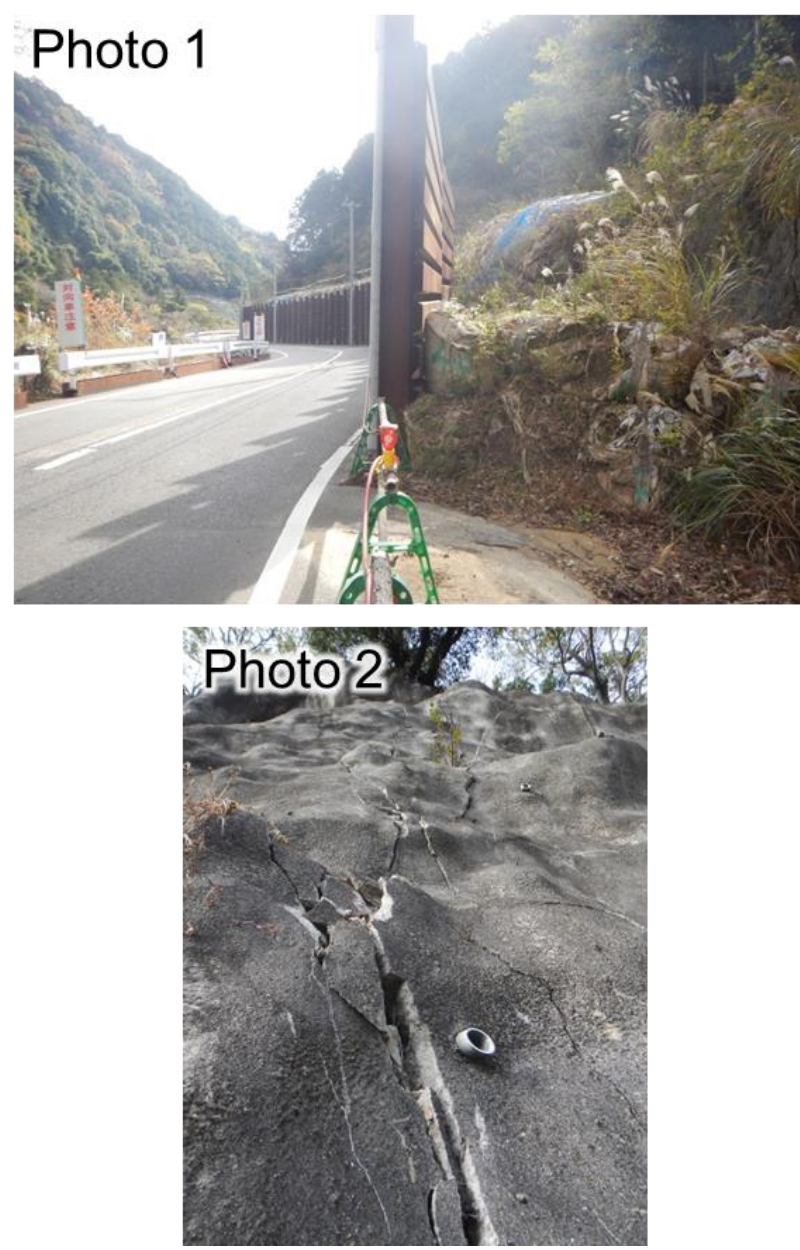

Figure 5. Field photos in Tanabe site.

(Photo 1: road replacement, Photo 2: fresh open crack of mortar spraying wall)

\subsection{Case of ALOS-2/PALSAR-2 data (9. Motoyama-b site)}

InSAR imagery in Motoyama-b site are shown in Figure 6. Change of LOS of approximately $8-9 \mathrm{~cm}$ in the direction of away from satellite was observed between October 10, 2014 and October 23, 2015. This phase change zone is located on landslide block. At the site, concrete block wall beside a forest road had some open crack and displacement (Figure 7). This concrete block wall was located beside landslide block. These open cracks (open crack 1, 2, 3 in Figure 7) have approximately $11 \mathrm{~cm}, 3 \mathrm{~cm}, 1 \mathrm{~cm}$ width, and north block of open crack 1 and 2 were shifted approximately $3 \mathrm{~cm}$ westward. The open crack 1 and 2 were somewhat old, and open crack 3 was new comparatively. We cannot judge whether these open cracks occurred during the phase change period. However, there is a high probability that the landslide block has moved recently too because open crack 3 was new. It is considered that InSAR imagery in Motoyama-b site detected this mass movement of landslide block. 


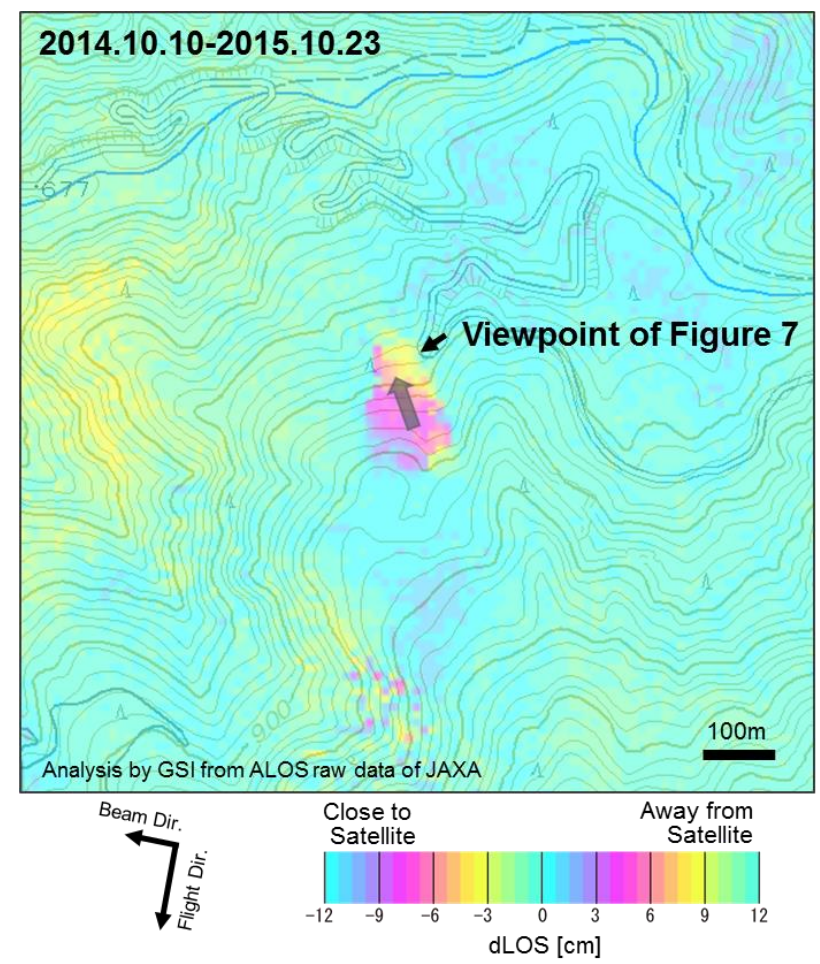

Figure 6. InSAR imagery between October 10, 2014 and October 23, 2015 on GSI Maps in Motoyama-b site. Grey arrow shows the direction of landslide movement estimated from field survey.

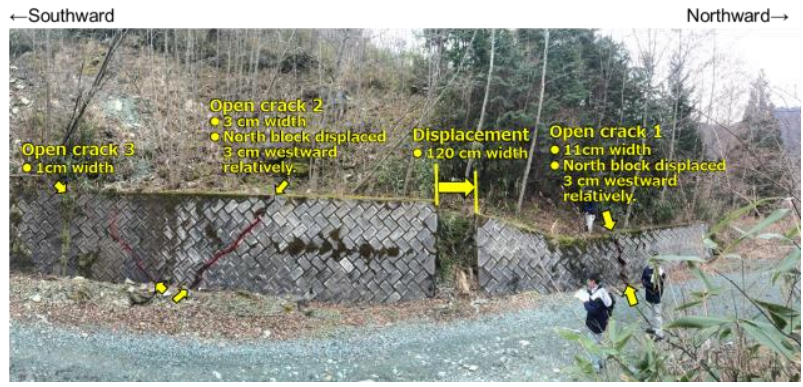

Figure 7. Field photo in Motoyama-b site.

Concrete block wall beside a forest road had some open crack and displacement.

\section{CONCLUSIONS}

We conducted field survey at the 10 sites of phase changes detected by ALOS/PALSAR and ALOS-2/PALSAR-2 interferograms. As a result, we identified deformation of artificial structures or linear depressions caused by mass movement at 9 sites. These results indicate that InSAR technique is able to detect on the continual slope deformation of landslide block for several years. There are exceptions to it, however. It is necessary that our rule of phase change interpretation of slope deformation is improved. In parallel with it, GSI of Japan will continue to perform the InSAR analysis throughout Japan. Therefore, we will be able to observe and monitor precursory slope deformation around landslide areas throughout Japan.

\section{ACKNOWLEDGEMENTS}

PALSAR data are provided from JAXA (Japan Aerospace Exploration Agency) through "Joint Cooperative Agreement between GSI and JAXA for observation of geographic information using Advanced Land Observing Satellite (ALOS) data." The ownership of PALSAR data belongs to JAXA and METI (Ministry of Economy, Trade and Industry). PALSAR-2 data are provided from JAXA through joint cooperative agreement between GSI and JAXA. The ownership of PALSAR-2 data belongs to JAXA. The products of the numerical weather model were provided by JMA (Japan Meteorological Agency) under the agreement between GSI and JMA.

\section{REFERENCES}

Amagai, T., Wada, K., Fujiwara, M., Suzuki, A., Tobita, M. and Yarai, H., 2007. Detection of Crustal and Ground Deformation Triggered by the Noto Hanto Earthquake in 2007 with InSAR. Journal of the Geospatial Information Authority of Japan, 113, pp. 3-11. (in Japanese)

Bürgmann, R., Rosen, P. A. and Fielding, E. J., 2000. Synthetic Aperture radar interferometry to measure Earth's surface topography and its deformation. Annual Review of Earth and Planetary Sciences, 28, pp. 169- 209.

Fujiwara, S. and Tobita, M., 1999. SAR interferometry techniques for precise surface change detection. Journal of the Geodetic Society of Japan, 45(4), pp. 283-295. (in Japanese with English abstract).

Fujiwara, S., Tobita, M., Murakami, M., Nakagawa, H. and Rosen, P. A., 1999. Baseline determination and correction of atmospheric delay induced by topography of SAR interferometry for precise surface change detection. Journal of the Geodetic Society of Japan, 45(4), pp. 315-324 (in Japanese with English abstract).

Kobayashi, T., Morishita, Y. and Yarai, H., 2015. Detailed crustal deformation and fault rupture of the 2015 Gorkha earthquake, Nepal, revealed from ScanSAR-based interferograms of ALOS-2. Earth Planets Space, 67:201.

Kobayashi, T., Tobita, M., Nishimura, T., Suzuki, A., Noguchi, Y. and Yamanka, M., 2011. Crustal deformation map for the 2011 off the Pacific coast of Tohoku Earthquake, detected by InSAR analysis combined with GEONET data. Earth Planets Space, 63, pp. 621-625.

Massonnet, D. and Feigl, K. L., 1998. Radarinterferometry and its application to changes in the earth's surface. Reviews of Geophysics, 36, pp. 441-500.

Riedel, B. and Walther, A., 2008. InSAR processing for the recognition of landslides. Advances in Geosciences, 14, pp. 189-194.

Sato, H.P., Miyahara, B., Okatani, T., Koarai, M., Sekiguchi, T. and Yagi, K., 2014. Detection of landslide surface deformation triggered by the 2011 off the Pacific coast of Tohoku earthquake using InSAR image. Journal of the Japan 
Landslide Society, 51(2), pp. 41-49. (in Japanese with English abstract)

Singhroy, V., Ohkura, H., Molch, K. and Couture, R., 2004. Monitoring Landslides and Volcanic Deformation from InSAR Techniques. Proceedings of ISPRS Congress XXXV (Commission VII, WG/5), pp. 570-573.

Suzuki, A., Amagai, T., Fujiwara, M., Wada, K., Tobita, M. and Yarai, H., 2008. Crustal Deformation Associated with the Niigataken Chuetsu-oki Earthquake in 2007 Detected by PALSAR/InSAR. Journal of the Geospatial Information Authority of Japan, 114, pp. 47-53. (in Japanese)

Tobita, M., 2003. Development of SAR interferometry analysis and its application to crustal deformation study. Journal of the Geodetic Society of Japan, 49(1), pp. 1-23 (in Japanese with English abstract).

Tobita, M., Fujiwara, S., Murakami, M., Nakagawa, H. and Rosen, P. A., 1999. Accurate offset estimation between two SLC images for SAR interferometry. Journal of the Geodetic Society of Japan, 45(4), pp. 297-314. (in Japanese with English abstract)

Tobita, M., Nishimura, T., Kobayashi, T., Hao, K.X. and Shindo, Y., 2011. Estimation of coseismic deformation and a fault model of the 2010 Yushu earthquake using PALSAR interferometry data. Earth Planet Science Letters, 307, pp. 430-438.

Une, H., Sato, H.P., Koarai, M., Yarai, H. and Tobita, M., 2008. Analysis of surface deformation induced by the Noto Hanto and the Chuetsu-oki Earthquakes in 2007 using synthetic aperture radar interferograms. The First World Landslide Forum, International Consortium on landslides (Poster Session Volume), pp.113-116. 